\title{
5 And then there was one: Kanashi numerals from borrowed superdiversity to borrowed uniformity
}

\begin{abstract}
Despite a long history of physical and social isolation from its surrounding communities, Kanashi exhibits several layers of borrowing from genealogically unrelated Indo-Aryan languages, which contribute substantially to the phenomenon described and discussed in this chapter, Kanashi's surprisingly rich array of mechanisms for forming numerals. The Kanashi numerals form a linguistic subsystem which holds both borrowed items and borrowed structures, and which also shows great variation, with up to four alternative ways of forming most complex numerals, a remarkable fact which deserves attention. This variety is now being displaced by wholesale adoption of Hindi numerals. On the basis of crosslinguistic data we discuss the quite different outcomes of borrowing from the same kind of source languages, but at different times.
\end{abstract}

Keywords: Kanashi, Kinnauri, numerals, numeral systems, Sino-Tibetan, IndoAryan, language contact

\section{Chapter overview:}

1 Introduction - 146

2 The Kanashi numeral systems -146

2.1 Nondecomposable numerals -148

2.2 Structure of the Kanashi numeral systems -150

2.2.1 Major part formation with minor part addition -152

2.2.1.1 Base 20 ST major part -152

2.2.1.2 Base 20 IA major part -152

2.2.2 Major part formation with minor part subtraction (only IA) - 153

2.2.2.1 Transitional base $20>10-153$

2.2.2.2 Pure base $10-153$

2.2.3 Minor part addition (only base 20) -153
2.2.4 Minor part subtraction (transitional base $20>10$ or pure base 10 ) -154

2.3 Numeral system 5: Modern Hindi numerals -154

3 Kanashi numerals in comparison - 155

4 Why are there IA borrowings in Kanashi at all? - 159

4.1 Background: Contact opportunities with IA speakers - 159

4.1.1 Religion -160

4.1.2 Collecting revenues -160

4.1.3 Seasonal migration -161

5 Why so many numeral systems? -161

6 Discussion, summary and outlook -165

A Attested Kanashi numerals in our fieldwork data -169 


\section{Introduction}

An intriguing fact which emerged when documenting Kanashi, a phenomenon which we have not seen much mention of in the literature, is that there are at least traditionally - several alternative ways of forming numerals in the language, and further that the numeral systems exhibit many items and structures borrowed into Kanashi, a Sino-Tibetan (ST) language, from - genealogically unrelated - Indo-Aryan (IA) languages.

This is the topic of this chapter, the rest of which is organized as follows. In Section 2 we present a description of the Kanashi numeral systems based on our own fieldwork data, followed by an investigation into their historical origins and a comparison to closely related or geographically close languages in Section 3. Section 4 is devoted to a discussion of possible reasons why so much borrowed material is found in a language whose speakers are well-known for keeping a clear distance to all outsiders. In Section 5 we address the question of the variation exhibited by Kanashi numerals, and summarize our conclusions in Section 6. Appendix A contains a listing of all Kanashi numerals found in our fieldwork data.

\section{The Kanashi numeral systems}

The presentation in this section is based mainly on the speech of three Kanashi speakers: one older male Kanashi speaker and two younger speakers, one man and one woman. At the time of the data collection the older speaker was about 50 years old, the younger male speaker around 22 years old and the female speaker around 28 years old. The female speaker had received some formal education. Both male speakers were illiterate; they had not received any formal education. All three speakers were born and brought up in Malana, the single village where Kanashi is spoken. Like other Kanashi speakers, they leave the village occasionally. All three could understand Hindi and Kullu Pahari, the locally dominant language, both IA languages. While the female speaker could speak Hindi quite well, the male speakers (especially the younger speaker) spoke a mixed Hindi with strong influence of their mother tongue Kanashi.

The data elicitation was done in Hindi. In addition to lexical items, we have also collected elicited phrases and sentences and some narratives. The following description of the Kanashi numerals is based on our fieldwork data, and also draws on the scant previous descriptions of Kanashi available in the literature. As can be seen in Appendix A to this chapter, not all numerals are attested in our ma- 
terial. ${ }^{1}$ Unless otherwise stated, Kanashi examples are provided here in phonemic transcription based on the description provided in Chapter 2 in this volume. ${ }^{2}$

Among older Kanashi speakers, several alternative systems for forming numerals up to 100 are in use, in addition to wholesale borrowing of the Hindi numerals. The concrete indication of this great variety is that we find up to three different ways of expressing the same amount in our data (four ways if we also reckon with the Hindi numerals), and if we extrapolate from attested combinations, there should be a maximum of four ways (five ways including the Hindi numerals). This variety comes from a set of partly independent choices both in constructing complex numerals and in selecting their components, to be further described below.

First, some terminology. Except for the lowest numerals, which tend to be monomorphemic, numerals in many languages are constructed according to the general pattern ${ }^{3}$

\section{$\mathrm{a} \times \mathrm{n} o p \mathrm{~b}$}

where "op" is some arithmetical operation, typically addition or subtraction. Note however, that there may, but need not, be elements in numerals explicitly expressing " $\times$ " ('times', '-fold', or the like) and the arithmetical operation ('on', 'and', 'from', 'less', etc.), but often the pattern is implicit, e.g., positionally indicated, as in Swedish sextiotre (sex-tio-tre [six-ten-three] ‘6 (x) 10 (+) 3’) 'sixty-three’.

\section{E.g.: $a \times 10 \pm b$ or $a \times 20 \pm b$}

(thus: $42=4 \times 10+2$ or $2 \times 20+2$ or $5 \times 10-8$ or $3 \times 20-18$ )

\footnotetext{
1 Note that this overview covers only cardinals. The little data that we have concerning ordinals in Kanashi point to overwhelming IA influence. Thus, even the lowest ordinals 'first' and 'second', at least as they are attested in our material, are IA borrowings (pela and dudza, respectively).

2 We have noted much phonetic variation across speakers in our data, where we find various degrees of adaptation of IA items - pucka $\sim$ putfas 'fifty'; sat $t^{h} \sim \int a t^{h} \sim \int \partial t^{h}$ 'sixty' - and also other differences, e.g., $a \sim u$, so that the name of the language itself appears both as kunashi (with older speakers) and kanashi (among younger speakers). See Chapter 4. Where we have recorded more than one variant of a certain IA numeral, we examined if the more standard IA pronunciation is found only in the speech of the literate speaker(s), in which case we chose the other variant, e.g. tfalis (literate speaker) tfali (speaker without any formal education; illiterate) 'forty'. Another guiding principle was frequency, where we have chosen the form which was provided by the majority.

3 Note that we must allow the quantities $a, n$ and $b$ to be atomic or (recursively) composite numerals for this pattern to work as a general characterization of the structure of (recursively binarybranching) numeral systems. Since we are dealing only with numbers in the range 1-100 here, this pattern serves us well in practice.
} 
The actual order of the elements may vary among languages. The quantity $n$ is known as a base of the numeral system, so that numbers are built from some multiple of the base modified by "op b", where $b$ then ranges from 0 to $n-1$, or, in other words: quantities are counted in groups of $n$. Two common numeral bases in the languages of the world, as well as the two bases encountered in the languages discussed here, are 10 - decimal numeral systems - and 20 - vigesimal systems (Comrie 2005). Numeral systems may exhibit more than one base, e.g. French, with both decimal and vigesimal structures. ${ }^{4}$ If more than one base is present, their distribution can be complementary (as in French or Danish), or they may be in free variation (as in Kanashi).

Below, we will refer to the multiples of the numeral base - "a×n" above - as the "major part", and the additive or subtractive elements - "op b" - as the "minor part" of the numeral expression. ${ }^{5}$

\subsection{Nondecomposable numerals}

The numerals in Kanashi which are not (synchronically) decomposable into simpler parts - "atoms" in the sense of J. H. Greenberg (1978) - are those for 1-20, some of the words for multiples of 10, and the numerals for 'hundred' and 'thousand'. Etymologically, the numerals $1-5$ and one of the two alternative terms for 20 are ST in origin, and all the others are IA borrowings. IA numerals for 1-5 and 20 also occur in Kanashi, but there is no simple ST numeral for 6 and above (except for 20, which is etymologically, but not synchronically, composite). Table 1 shows the Kanashi numerals 1-20, giving the origin for nondecomposable items and an analysis for composite numerals.

The great diversity in numeral formation patterns in Kanashi which we describe in detail below is characteristic of higher, composite numerals, not the nondecomposable lower numerals. Among the latter, 1-5 (and 20) have at most two variants (ST and IA), and for expressing the numerals 6-16 we have only found one term per item, IA in origin. The diversity in numeral formation starts with the

4 Here we are not referring to the common case where we find successively larger bases expressing powers of some lower base, as when $100=10^{2}, 1000=10^{3}$, etc., but a situation where alternative bases are used as "paradigmatic alternatives" in positions where the other base would be expected.

5 There are other (rarer) systems which do not conform to this pattern, e.g. systems without any base (Comrie 2005; Hammarström 2010), or the "numeral system! overcountingovercounting" systems mentioned by Comrie (1999) and Mazaudon (2010), referring back to Menninger (1969: 76-80) as the scholar who first introduced this term, e.g., Finnish kuusitoista (kuusi-tois-ta [sixsecond-PARTITIVE] 'six of second (ten)') 'sixteen'. 
Table 1: Kanashi numerals 1-20

\begin{tabular}{|c|c|c|}
\hline Gloss & Kanashi & $\begin{array}{l}\text { Origin (Source: IA: Turner 1966; ST: STEDT 2016; Matisoff } \\
\text { 2003) }\end{array}$ \\
\hline 'one' & $\begin{array}{l}i \cdot d \\
e k\end{array}$ & $\begin{array}{l}\text { ST: *it } \\
\text { IA: Turner } 2462 \text { ếka }\end{array}$ \\
\hline 'two' & nif & ST: *gnyis; Sino-Tibetan (ST): *g-ni-s /*g-nis \\
\hline 'three’ & fum & ST: *gsum; ST: *g-sum \\
\hline 'four' & pu & ST: *pwa (breadth of four fingers) \\
\hline ‘five’ & $\eta a, n a$ & $\mathrm{ST}:{ }^{*}$ na \\
\hline ‘six’ & $t^{\text {hh }} a$ & IA: Turner 12803 șáș \\
\hline ‘seven’ & sat & IA: Turner 13343 sắpta \\
\hline ‘eight’ & $a t^{h}$ & IA: Turner 941 așțấ \\
\hline 'nine' & nao & IA: Turner 6984 náva \\
\hline 'ten’ & das & IA: Turner 6227 dáśa \\
\hline ‘eleven’ & gjara & IA: Turner 2485 ếkādaśa \\
\hline 'twelve' & bara & IA: Turner 6658 dvắdaśa \\
\hline 'thirteen’ & tera & IA: Turner 6001 tráyōdaśa \\
\hline ‘fourteen’ & toda & IA: Turner 4605 cáturdaśa \\
\hline ‘fifteen’ & pandra & IA: Turner 7662 páñcadaśa \\
\hline 'sixteen' & sola & IA: Turner 12812 șốḍaśa \\
\hline \multirow[t]{2}{*}{ ‘seventeen’ } & Jumis kam nidka & [3:is less 20] \\
\hline & suta:ra & IA: Turner 13146 saptádaśa \\
\hline \multirow[t]{2}{*}{ 'eighteen’ } & nif kam nidza & [2 less 20] \\
\hline & $t^{h}$ ara & IA: Turner 946 așțấdaśa \\
\hline \multirow[t]{2}{*}{ 'nineteen' } & i:dis kam nicka & [1:is less 20$]$ \\
\hline & unni & IA: Turner 2411 ūnavimiśati \\
\hline \multirow[t]{2}{*}{ 'twenty' } & nicka & ST: [two:ten] (cf. Kinnauri nicka < nif 'two' + se 'ten') \\
\hline & $b i$ & IA: Turner 11616 viṁśatí \\
\hline
\end{tabular}

numeral 17, which exhibits one nondecomposable (sutara; IA) and one composite variant (Jumis kam nicka [3:is less 20]).

Konow (1909) and Sharma (1992) provide brief descriptions of the Kanashi numerals. Both note that higher numerals (except 20) are of IA origin, and that Kanashi uses both the IA decimal system and a vigesimal system. Konow suggests a gender-based tendency in the use of the IA decimal system and numerals based on the vigesimal system: "Higher numbers are counted in twenties, though the Aryan method of reckoning in tens is also commonly used by men, while the women stick to the other way." (Konow 1909: 444). This gender-based distribution of the decimal and the vigesimal system is not found in our material. As we will seen below, both the IA decimal system and the vigesimal system were provided by an older male speaker, along with some other numeral systems. Konow (1909) also notes a variation between [n] and [n] in 'two' (nish, nyish). This is also 
not found in our material. We consistently got [nif] from both older and younger speakers.

\subsection{Structure of the Kanashi numeral systems}

As opposed to some modern IA numeral systems, which are characterized by extreme irregularity, so that, e.g., the Hindi numerals 1-100 are in effect synchronically unanalyzable (Berger 1992: 243-245), all the Kanashi structures found in our data are quite regular. The choices characterizing the different ways of composing numerals in Kanashi are choice of ${ }^{6}$

(a) numeral base: 20, 10 or transitional 20>10 (see Section 2.2.2.1)

(b) language of origin for major parts of numerals: ST or IA

(c) operation performed on minor parts of numerals: addition or subtraction

Theoretically, this would yield $3 \times 2 \times 2=12$ possible numeral systems, but the choices are not completely independent, and on the whole only four different combinations are found in our material. They are:

(A1) base $20+\mathrm{ST}+$ addition

(A2) base $20+\mathrm{IA}^{7}+$ addition

(S1) transitional base $20>10+\mathrm{IA}+$ subtraction

(S2) base $10+\mathrm{IA}+$ subtraction

6 Interestingly and even unexpectedly - and with one minor exception involving the item sare '+half' - the linear order among components is not variable; multiplication has smaller before larger (3×20), as has subtraction, while with addition the order is larger before smaller $(20+3)$. On the one hand, this seems to be a common parameter for variability in languages (see Section 5), which makes its absence remarkable in a numeral system with so much variation in other respects. On the other hand, in the cases of multiplication and addition the orderings attested in Kanashi are the most frequent across languages, according to J. H. Greenberg (1978).

7 IA 'twenty' as the base is not found at all in our material. All numerals involving the vigesimal system use ST nidza 'twenty’. However, Grierson (1928: s.v. Hundred (13)) has ra biya [five $(\times)$ twenty] 'hundred' (nabeeha in Harcourt 1871: 378). 
Examples: ${ }^{8}$

(1) (1a) A1: 'fifty five' nif nidzau dze pandra [2 ( $\times$ ) 20:u plus 15]

(1b) A1: 'thirty two' nidzau dze bara [20:u plus 12]

(1c) A2: 'seventy six' sat $t^{h} \boldsymbol{u}$ dze sola [60:u plus 16]

(2) (2a) S1: 'sixty nine' i:dis kam sare sat ${ }^{\boldsymbol{h}}$ [1:is less +half 60]

(2b) S2: 'fifty five' yais $\underline{\mathbf{k a m}_{\mathbf{m}}} \boldsymbol{s a t}^{\boldsymbol{h}}$ [5:is less 60]

(2c) S2: 'fifty five' pãtf kam sat ${ }^{\boldsymbol{h}}$ [5 less 60]

Another way of (partly) expressing this would be to say that ST major parts imply addition (A) of minor parts, while subtraction (S) of minor parts implies IA major parts (except 'twenty'; see below). Note that addition occurs with both ST and IA major parts, hence the (one-way) implication.

Regarding choice (b) above (the language of origin), it concerns specifically the major parts of numerals (see $1 \mathrm{c}$ and $2 \mathrm{~b}$ ). As for the minor parts, the numerals 1-5 can be both ST and IA (see $2 \mathrm{~b}$ and $2 \mathrm{c}$ ), and the numerals 6-19 are only IA. The choice of language of origin for those minor parts where this is an option does not influence the structure of numerals. In numerals of type (A1), the major parts are expressed using ST elements (see 1a and 1b). In type (A2) these are simply replaced by the corresponding IA elements, i.e., 20, 40, 60 and 80, preserving a basically vigesimal system (see 1c).

In numerals of type (S1), base 10 is introduced - or the values half-way between multiples of 20 are given special treatment - using the (IA) expression sare '+half', i.e., 70 is expressed as [60 +half] or [+half 60] in example (2a). As shown in (2b), in type (S2) the IA words are used for all multiples of $10,{ }^{9}$ making it a pure base-10 system (i.e., decimal). ${ }^{10}$

Exceptionally, subtraction also occurs with the ST numeral nidka '20' in our data, where the numerals 17, 18 and 19 are formed as

8 Here and below IA elements will be indicated in examples in bold with underlining and inferred - unexpressed - instances of multiplication and addition between separate words will be shown in the glossing of numerals by “ $(\times)$ ” and “(+)”, respectively. Even though the element dze is glossed as 'plus' in the examples, so far we do not actually know its meaning or its origin. For a discussion of this and of the suffixes -(i)s and - $u$, see Section 3.

9 These IA items are borrowed from some IA language with a decimal numeral system, and not one whose numeral system is vigesimal, as is the case in several Western Pahari languages. Kullu Pahari has both systems (see also Section 2.3 below).

10 Some modern IA numeral systems - notably that of Hindi - are such that the structure of major parts is not synchronically obvious (because of sound changes), so that these systems are classified as decimal only by virtue of their minor parts cycling through 1-9 rather than 1-19. 
(3) 'seventeen' Jumis kam nidka [3:is less 20]

'eighteen' nif kam nidka [2 less 20]

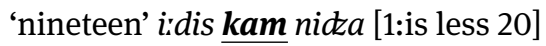

With the pure base-20 numerals (types A1 and S1), intermediate quantities are formed by the operation of addition, i.e., the formula is [a $\times 20+b$ ], where a is in the range $2-4$, and b ranges from 1 to 19 . With types S1 and S2, the pattern is [b subtracted from $a$ ], where $a$ is on the form either [IA.multiple.of.10] or [IA.multiple.of.20 +half]/[+half IA.multiple.of.20].

\subsubsection{Major part formation with minor part addition}

\subsubsection{Base 20 ST major part}

ST major parts are built from the expression nidka 'twenty', which is presumably etymologically compound [two+ten] but synchronically monomorphemic, since the ST word for 'ten' is not attested in Kanashi, but has been replaced by the IA word das 'ten'. ${ }^{11}$ Cf. Kinnauri nidza 'twenty' < nif 'two' + se 'ten' (Saxena 2017: 762). Hence: nif nicka [2 (×) 20] 'forty', fum nidka [3 (×) 20] 'sixty', pu nicka [4 (×) 20] 'eighty'. Minor parts in the range 1-19 are added to the major parts according to a pattern described below. Thus, 'thirty' is, for example, expressed by nidzau dze das [20:u plus ten], and 'fifty-nine' is nif nidkau dze unni [2 (

\subsubsection{Base 20 IA major part}

The only difference from the preceding pattern is that the ST major part is replaced by the corresponding IA numeral. Practically, this means that the IA expressions for 'thirty', 'fifty', 'seventy' and 'ninety' do not appear here, but are instead expressed as, e.g., sat ${ }^{h} \boldsymbol{u}$ dze $\underline{\text { das }}$ [60:u plus 10] 'sixty and ten'. Consequently, this pattern is at heart vigesimal, even if the IA numerals substituting for ST major parts have a decimal etymology.

11 Although according to Hodson (1913: 329), "Dārmiyā [Darma], Kanawri [Kinnauri], Kanashi, Chamba Lahuli [Tinani], and Rangkas have forms sai or sā” for 'ten'. This may be a mistake, since the stated source of Hodson's data, LSI vol. 3 (Konow 1909), does not list such a form for Kanashi, neither in the Kanashi grammar sketch (Konow 1909: 444) nor in the standard word list (Konow 1909: 532). 


\subsubsection{Major part formation with minor part subtraction (only IA)}

\subsubsection{Transitional base $20>10$}

As with the pure base 20 IA major part, only the IA terms for 'twenty', 'forty', 'sixty', and 'eighty' appear in this pattern. However, instead of expressing 'thirty', etc., as 'twenty and ten', etc., these are formed using the (IA) expression sare '+half'. ${ }^{12}$ The order of the elements seems to be free; sare can be placed before or after the multiple of 20: $\underline{\text { sare }} \underline{\boldsymbol{s a t}^{\boldsymbol{h}}}$ [+half 60] '70' a si sare [80 +half] '90'.

\subsubsection{Pure base 10}

In this pattern, the major parts are simply the IA numerals for the decades: $i$ :dis kam pudza [1:is less 50] '49'; sat kam pudza [7 less 50] '43'.

\subsubsection{Minor part addition (only base 20)}

The pattern here is

$$
\text { major.part(-u) (dze/ke) minor.part }
$$

The (base-20) major part can be ST or IA as described above; examples:

(4) 'twenty three' nidza-u dze Jum [20.ST.base.20-u plus 3]

'sixty five' Jum nicka-u dze ya [3 (×) 20.ST.base.20-u plus 5]

'sixty seven' Jum nidza-u dze sat [3 ( $\times$ ) 20.ST.base.20-u plus 7]

'sixty seven' sat $\boldsymbol{t}^{\boldsymbol{h}}$-u dze sat [60.IA.base.20-u plus 7]

'seventy' sat t $^{\text {-u }}$ dze das [60.IA.base.20-u plus 10]

While our language consultant provided most of these numerals with dze, he said that dze here can always be replaced by ke without any apparent difference. Furthermore, $d z e / k e$ can also be omitted altogether. There is also one instance in our data (nidza dze ya [20 plus 5] 'twenty five') where - $u$ does not appear.

12 [sa:re] (Hindi) or a similar form for '+half' occurs in many IA languages. For example: Punjabi sādhe, Bengali sāre, and Gujarati sāra (Berger 1992); Kotguru (Koṭgurū), Cameali (Camealī), Bhateali (Bhațeālī), Curahi (Curāhī), and Bhadrawahi (Bhadrawāhī) sāẹhē (Bailey 1908). It occurs with the numerals 3 and above, where it has the interpretation '+half'. According to Berger (1992: 279), it "has developed from Sanskrit sārdha (< *sa-ardha 'provided with a half')”. 


\subsubsection{Minor part subtraction (transitional base $20>10$ or pure base 10 )}

The pattern here is

$$
\text { minor.part-(i)s } \underline{\text { kam }} \text { major.part }
$$

The element $\underline{\text { kam }}$ 'less' is IA; examples: ${ }^{13}$

(5) 'nineteen' i'dis $\underline{\mathbf{k a m}}$ nidza [1:is less 20]

'twenty eight' nifis kam derbija [2:is less 1.5:20]

'sixty seven' Jumis kam sare sat ${ }^{\boldsymbol{h}}$ [3:is less +half 60]

'eighty one' unnis kam fo [19:is less 100]

This pattern mixes base 20 and base 10. The minor part consequently ranges between one and 19, but we see both cases where the major part is a multiple of 20 and those where the major part is an odd multiple of 10. The minor part could be ST (e.g. Jumis kam nidza [3:is less 20]) or IA (e.g. sat kam pudza [7 less 50] '43'). It would be reasonable to assume that a minor part 10 or larger would only be used with a major part that is a multiple of 20, whereas odd multiples of 10 should allow only minor parts with the value nine or less. However, there are only a few examples of this pattern among our fieldwork data, making it hard to confirm or reject this assumption.

The suffix -is on the minor part occurs when it ends in a consonant and -s occurs when it ends with a vowel, but there is one instance (yais $\underline{\mathbf{k a m}} \mathbf{s a t}^{\boldsymbol{h}}$ [5:is less 60] '55') where -is occurs with a numeral ending in a vowel ( $\mathrm{ya}$ 'five'). Further, the occurrence of -(i)s seems optional, as we have instances of the same numeral both with and without -(i)s before kam; for example:

(6) 'twenty eight' nifis kam derbija [2:is less 1.5:20]

'eighteen' nif kam nidza [2 less 20]

\subsection{Numeral system 5: Modern Hindi numerals}

Apart from the four numeral systems described above, the regular modern Hindi numerals are increasingly gaining ground. Examples of some Hindi numerals in Kanashi are provided below. Table 2 contains a comparison of these Kanashi numerals with those in Hindi, in Kullu Pahari (ktx; the dominant regional language)

$13 \underline{\operatorname{der}}$ ' 1.5 ' is an IA borrowing. 
and Mandeali (mjl). Both the latter are Western Pahari IA languages presumably representative of the donor language for the older IA elements in Kanashi numerals. ${ }^{14}$ The older borrowed IA words for 'thirty', 'fifty', 'seventy', and 'ninety' have clear base-10 etymologies. Their shape together with linguistic geography points to some Western Pahari language as the source (see Section 3). Equally clearly, the shape of the recent items listed in the "Kanashi" column in Table 2 indicates that their source is not Kullu Pahari or some other Western Pahari language, but Hindi.

Table 2: Some borrowed modern Hindi numerals in Kanashi (Hindi, Kullu Pahari, and Mandeali numerals from <https://mpi-lingweb.shh.mpg.de/numeral/>)

\begin{tabular}{lllll}
\hline Gloss & Kanashi & Hindi (IA) & Kullu Pahari (IA) & Mandeali (IA) \\
\hline 'five' & pãtf & pāch [påt] & pand3 & pandz \\
'twenty one' & ikkis & ikkais [ık:is] & $i k k i$ & Ikki \\
'twenty two' & bais & bais [bais] & bai & bai \\
'twenty three' & teis & teis [țeis] & tirei, trei & tei \\
\hline
\end{tabular}

The four numeral strategies described above (A1, A2, S2, S2), were provided primarily by older Kanashi speakers. According to our primary older language consultant, the four patterns are interchangeable, i.e., they are not functionally or situationally differentiated, and he very happily provided more and more examples of Kanashi numerals using the four numeral systems, while younger Kanashi speakers (both males and females) used only Hindi numerals, and when specifically asked about their judgements of the four numeral strategies, they did not recognize the higher numerals formed with $d z e / k e$, and just laughed and said that they do not know what this is. They provided instead the Hindi numerals.

\section{Kanashi numerals in comparison}

Kinnauri and Bunan are two other ST languages of Himachal Pradesh which are closely related to Kanashi (see Chapter 1). Comparing the numeral systems of these languages to that of Kanashi will hopefully help to throw light on the

14 We know too little about the prehistory of Kanashi to say which IA language would be the most likely donor language for the older stratum of borrowed IA numerals. Kullu Pahari is geographically closest at the present time, and Mandeali is spoken in an area in-between the present locations of Kanashi and its closest ST relative Kinnauri. 
somewhat unexpected situation in Kanashi and also provide some additional information about the structural elements of the Kanashi numeral systems.

As opposed to Kanashi, both Bunan and Kinnauri preserve an inherited ST numeral system, at least up to and including 'one hundred'. In both cases the common inherited ST system is vigesimal. ${ }^{15}$

Additionally, and similarly to Kanashi, in both Kinnauri and Bunan the Hindi numerals can be freely used, since both communities are in effect at least bilingual, with Hindi as the prestige language and the language of wider communication for interacting outside the own language community.

According to Widmer (2017: 309-311), in the case of Bunan, the traditional numerals are nowadays used almost exclusively for lower numbers up to 20. The main numeral system in daily use is a decimal system borrowed from Tibetan, which was the culturally dominant language until the mid-20th century.

Traditional Bunan numerals are vigesimal with minor part addition, i.e., they correspond to the Kanashi A1 pattern. Examples (Bunan [Widmer 2017: 307-308]):

(7) 'four' pi:

'twenty' nidza

'ten' t6uj

'twenty-four' nidza=ki pi [twenty=GEN four]

'fourteen' tcupi [ten:four]

'thirty-four' nidza=ki toupi [twenty=GEN ten:four]

'eighty' pi: nidza [four $(\times)$ twenty]

Kinnauri also shares some features with Kanashi in the way numerals are formed. Kinnauri exhibits basically two strategies for forming complex numerals:

(A) Base 20 major part with minor part addition

(S) Transitional base 20>10 major part with minor part subtraction

Examples (Kinnauri [Saxena 2022]):

(8) A: 'sixteen' sorug [ten:o:six]

'thirty-seven' nidzo sostif [twenty:o ten:o:seven]

'sixty-nine' Jum nidzo gui [three $(x)$ twenty:o nine]

(9) S: 'thirty-seven' Jum maits nifnidza [three is.not two:twenty]

'fifty-seven' Jumindza pay fum ma:ts [three:twenty DAT three is.not]

15 Proto-ST is reconstructed as having a decimal numeral system, however. 


$$
\begin{aligned}
& \text { ‘seventy-seven' Jum kam pa nidza [three less four }(\times) \text { twenty] } \\
& \text { ‘eighty-seven' Jum ma:ts panidzo se [three is.not four:twenty:o ten] } \\
& \text { 'ninety-seven' ra pay Jum ma:ts [hundred DAT three is.not] } \\
& \text { 'ninety-seven' Jum maits ra [three is.not hundred] }
\end{aligned}
$$

The A pattern in Kinnauri corresponds to that seen in traditional Bunan numerals as well as to the Kanashi A1 construction.

The Kinnauri S pattern represents a decimal overlay on the basic vigesimal numeral system, since the minuend is the next multiple of 10 (not 20), as can be seen in the item 'eighty-seven' above, which means that the subtrahend will always fall in the range 1-9. Apparently the element glossed 'less' in the S structures can always be expressed either with the negated ST copula ma:ts or with the borrowed IA item kam, the latter being the same as in the Kanashi S1 and S2 structures. There are two variants of the $\mathrm{S}$ structure, one where the minuend comes first followed by the dative marker pan, after which the subtrahend and ma:ts/kam follow, i.e. 'to $\mathrm{X}$ is not Y' or ' $\mathrm{X}$ does not have $\mathrm{Y}$ '. The ordering of elements in the other variant corresponds to the Kanashi S1 and S2 patterns, i.e., [subtrahend less minuend].

While it is clear that kam 'less' is an IA borrowing in Kanashi, the etymology of -(i)s normally appearing before it on the subtrahend is unknown. Possibly it is to be identified with the instrumental (and ergative) marker -(i)s, which some authors have suggested goes back on an older ablative (Zeisler 2011), making the gloss something like $\mathrm{x}$-is kam $\mathrm{y}$ ' $\mathrm{y}$ from $\mathrm{x}$ '.

The $-u$ linking major and minor parts in Kanashi could tentatively be identified as the possessive suffix (see Section 2.2.4.5 in Chapter 3). In that case, it has a counterpart in Kinnauri - $o$, a possible genitive suffix allomorph also in Kinnauri (although the same Kinnauri suffix can also be an allomorph of the dative or locative morpheme in certain contexts; Saxena 2017: 759-760).

As mentioned above, the origin of the element $d z e / k e$ in Kanashi numerals is unknown. The following observations seem relevant here.

In the corresponding Bunan numerals an element $k i$ appears between the two parts, which is identified as the genitive clitic in Bunan (Widmer 2017: 307); see the Bunan examples presented above. Similarly, in Kinnauri addition of parts of numerals is expressed with an element which can be identified as a genitive suffix. Additionally, the extinct ST language Zhangzhung, a West Himalayish language according to most authors (see Chapter 1), is reported to have a suffix -żi/-ci expressing a "Genitive or Causal value" (Thomas 2011: 229). One explanation for the Kanashi construction could be that it is an instance of multiple exponence, where the same content is expressed by two different adjacent morphs. This forms one of the four multiple exponence patterns described by Harris (2017) as being cross- 
linguistically dominant. A weakness with this analysis of the Kanashi construction is that we have not found the item $d z e / k e$ used as a genitive clitic elsewhere in the language. On the other hand, Kanashi does show instances of stacked genitives, e.g., $b u f-u-k(a)$ [rope-Poss-Poss] (see Chapter 3).

Zhangzhung also has another suffix -tse/-ce with "Ablatival or Causal sense" which may be identified with the "Ablatival che (ce) of Kunāwarī [Kinnauri]" (Thomas 2011: 23). Relevant in this context is that the modern form of the Kinnauri ablative suffix $-t$ ' is often combined with locative $-o$ into $-o-t$ [-LOC-ABL] (Saxena 2017: 760). In addition to expressing a concrete spatial sense of 'from inside', the Kinnauri [-LOC-ABL] combination is used to mark the basis of comparison in comparative constructions (Saxena 2017: 762), which semantically is close to 'plus'/'in addition to'. Kanashi has a corresponding structure: - $a$-ts [-LOC-ABL], e.g. tfamtfin- $a$-ts [spoon-LOC-ABL], but the differences in form between - $a$-ts and $-u d z e / k e$ are non-trivial.

As a third possible origin of this construction, we note that Kanashi has a dative ending -udz, e.g., tfara-udz [child-DAT]. Given that there are clear cases of [-Poss-cx] as alternatives to [-cx] in the Kanashi case system (e.g., -ran [-сом] $-u$-ran [-POSS-COM] and - di [-ADE] $\sim-k a-d i[$-POSS-ADE] $\sim-n$ - di [-POSS-ADE] $\sim-u-d i$ [-POSS-ADE]; see Chapter 3), a promising hypothesis would be that -u dze represents a frozen earlier stage in the diachronic development which led to the presentday dative marker in Kanashi, i.e. a parallel to the Kinnauri use of dative in complex numerals, e.g. 'fifty-seven' and 'ninety-seven' in (3).

Further investigation is clearly needed before we can say anything more certain about the origin of $-u d z e / k e$ in Kanashi.

All in all, the Kanashi and Kinnauri numeral systems are quite similar. There are differences in details, but the main difference is the almost complete absence of IA elements in the Kinnauri numerals as opposed to their ubiquitousness in Kanashi. Impressionistically, Kanashi exhibits a heavily "relexified" ST numeral system very close to the one seen in Kinnauri, notably including both the A and S variant structures. The greater commonalities that we have seen between Kanashi and Kinnauri compared to Kanashi and Bunan serve to further support a closer genealogical classification as presented in Chapter 1 above.

As for the origin of the IA elements in the Kanashi numeral systems, the following observations can be made. There are at least three layers of IA borrowing discernible in Kanashi. Firstly, for other items than numerals, Kanashi shares a particular set of unique loanword adaptation mechanisms with Kinnauri. In both languages, many borrowed IA nouns have a suffix-like element not present in any of the modern IA languages spoken in the area, nor in related ST languages (see Chapter 6). This indicates that the borrowing has occurred in their common protolanguage, but not earlier. On the other hand, we have seen that Kinnauri still pre- 
serves an essentially ST numeral system without much IA influence. Hence, and secondly, the massive replacement of ST numerals by IA elements in Kanashi has taken place sometime after the split-up of Kanashi and Kinnauri. This older layer of borrowed items and structures in the Kanashi numerals probably originates in some local IA - Western Pahari or possibly Dardic - variety. The forms of IA items on the whole coincide with those given in descriptions of some of these languages (e.g., Bailey 1908), e.g., So 'hundred' rather than (Hindi) so, and bi 'twenty' rather than bis, etc. The borrowed IA numerals in Kanashi reflect a decimal system, even though many local IA languages have vigesimal systems. The order of units and decades found in the numerals in local IA varieties is typically the same as in Hindi, and opposite to that of Kanashi (or Kinnauri). The Kanashi numerals thus arguably represent a case of IA lexical replacement in ST structures. Thirdly, we are now observing wholesale replacement of this older borrowed system by freshly borrowed Hindi numerals, as shown above in Table 2.

\section{Why are there IA borrowings in Kanashi at all?}

Given the traditional degree of isolation of the Kanashi community as described above, one is surprised to find a large number of IA lexical items and some non-ST grammatical patterns in Kanashi. As described in Section 2, even the traditional numeral systems contain a large number of IA elements.

At least in the case of the traditional numerals, the original reason should not have been a need to fill lexical gaps, since, as we have seen, the closely related languages Kinnauri and Bunan have full-fledged indigenous ST numeral systems, whose elements in many instances are reconstructible all the way back to ProtoSino-Tibetan (Matisoff 1997). Hence, the reason for Kanashi borrowing so heavily from IA in this area must be sought elsewhere.

\subsection{Background: Contact opportunities with IA speakers}

To account for this massive presence of IA loanwords in Kanashi, we will now present some relevant economic and religious aspects of this community, which suggest that Kanashi speakers have had regular, almost ritualized contacts with the members of some surrounding villages in Kullu (all IA speaking), even though in their day to day life the contact has traditionally been minimal (Tobdan 2011). 


\subsubsection{Religion}

The Malana village god - referred to as Jamlu devta - is revered both in Malana and in several other villages in Kullu. According to the legend, Jamlu devta is kin to village gods of other villages in Himachal Pradesh (both IA speaking villages and ST speaking villages). Such a village is referred to as a deoghar (an IA word meaning 'god-home') of Jamlu devta. These villages show a number of similarities in how they perform the rites and also in the names of the office-bearers. For example, Jana village is a deoghar of Jamlu devta, whose ritual procedures as well as the names of the office-bearers for the Jamlu devta are the same as in Malana. In the Pulag village (which is geographically closest to Malana), in addition to the similarities in the religious rites and the names of the office-bearers, their administrative system as well as the division of the village in an upper and a lower part is the same as in Malana. Festivals are organized both in Malana and in the various deoghars. The dates of these festivals in the various deoghars are decided in consultation with Malana. The members of the Malana community visit many of these villages at regular intervals. Similarly, the members of other villages come to Malana once or twice each year, staying in Malana for a week or so where they interact closely with the locals. The visits of IA speaking guests from deoghars is such an integral part of the Kanashi community that there is a designated large house in Malana to provide lodging for the visiting members of other deoghars. There is also a community food storeroom which is used for preparing food for these visiting guests and a group of four functionaries is selected each year from among the Malana families to take care of the needs of the guests during various village festivals, which are held several times each year. Such contacts provide regular and perodically intensive opportunities for language contact between the IA languages of Kullu and Kanashi. As often in language contact situations, the contacts are linguistically asymmetrical, in that all interactions will be in some IA language and not in Kanashi.

\subsubsection{Collecting revenues}

In modern times, the sources of income for most Kanashi families are agriculture, forestry and animal husbandry. Earlier, they used to barter clarified butter, honey, game and herbs with people of the lower Himalayan region, in exchange for rice, corn, rock salt and iron for tools. In modern times they also buy modern amenities. The Kanashi community as a whole generates income by collecting revenues from other villages and deoghars, according to their traditional practices. It is said that Jamlu devta owns land in some deoghars outside Malana, from which it gets part 
of the yield. To take care of collecting revenues from outside Malana, there is an organized administrative body in Malana. A group of five officials is elected each year in Malana, whose main function is to visit villages and deoghars of Jamlu devta to collect revenue which is provided in kind. For this purpose, they are away from Malana for longer periods of time, visiting various parts of Kullu where they interact with IA speakers. Revenue collection naturally involves discourse where (higher) numerals are used, meaning that the knowledge of IA numerals receives constant reinforcement among the Kanashi speakers.

\subsubsection{Seasonal migration}

There are two groups of Kanashi speakers who migrate to the plains in lower Himalayan regions during winter. First, since not much grows in and around Malana during the winter months, some practice transhumance, i.e., they take their herds and move to lower regions for the winter. Second, some members of Malana families, including women and children, spend a month or so in the deoghar villages of the lower regions. These situations also provide ample opportunities for language contact between IA languages and Kanashi.

\section{Why so many numeral systems?}

The many different ways in which a given quantity can be expressed in Kanashi struck us as worthy of investigation. We have not come across any systematic broader treatment of this topic in the linguistic literature. Somewhat paradoxically, numeral systems in languages seem to be both well-studied and underresearched at the same time. The components and structures making up numeral systems are generally well-known, both majority patterns attested across many languages (Comrie 1999; 2005), and rarer or even unique structures (Hammarström 2010). The range of possible systems has been thoroughly explored and described, in terms of number of items (none, few, many, infinite), bases, structures (how items can be combined and how the combinations are interpreted in arithmetical terms).

The kind of intra-language variation that we find in traditional Kanashi numerals has received much less attention, however, and in fact seems to be underdocumented. Perhaps this is because of the doubly peripheral position of numerals in language: as is well-recognized, they straddle the boundary between grammar and lexicon, in that they exhibit both grammatical - closed-class - and lexi- 
cal - open-class - behavior at the same time. As a case in point, Wintu (wit; Wintuan) exhibits alternative ways of forming decades, but this cannot be found out from Pitkin's Wintu grammar (1984). Instead, information about the numerals is provided under the entries for 'ten' and 'twenty' in his Wintu dictionary (1985: s.v. tiqeles and ketewint ${ }^{h} u h$ ), where we learn that "valuables were subject to vigesimal rather than decimal count", and some alternative formations are listed: "ḱetewin$\mathrm{t}^{\mathrm{h}} \mathrm{uh}$ tiqeles $\lambda$ omi thirty (also panu $\lambda$ tiqeles)" (Pitkin 1985: 695, s.v. ketewint ${ }^{h} u h$ ).

Going through numerous individual language descriptions, we have come up with some cases where alternative numeral systems live side by side. Thus, Moghol (mhj; Mongolic) is reported as having four parallel sets of cardinals (Weiers 2003; Blažek \& Schwarz 2016), if the use of Persian numerals is taken into account.

Further, several IA and ST languages of the Himalayan region (as nondominant languages elsewhere) have more than one parallel numeral system. Often there are two systems, one more indigenous and the second a borrowing from a surrounding dominant language, local, regional or national. In each of these cases, the dominant language's numeral system is increasing in use, and the role of the indigenous numeral system is becoming more restricted (see Matisoff 1997: 12-16). Mazaudon (2010: 124-131) notes that Dzongkha uses two systems: a decimal system borrowed from Tibetan which is used in formal contexts and in writing, and a vigesimal system used elsewhere. As mentioned in Section 3, Bunan has three parallel systems. Yliniemi (2019) reports that Denjongke (sip; also referred to as Sikkimese; ST) has a parallel vigesimal and decimal numeral system. Both systems are made up entirely of inherited (ST) elements, and they seem to have complementary application domains: "some initial observations[:] the vigesimal system is used at least when talking about prices of items [...], age of people [...] and number of people[, while t]he decimal system is used for pointing out the year when something took place [...], the number of years since something happened [...] and dates" (Yliniemi 2019: 124). It may well be that the presence of multiple numeral systems is a common feature in languages, but this is difficult to find out since language descriptions generally seem to assume one numeral system by default, as it were (Mazaudon 2010).

The few more general discussions that we have found of such situations seem to conclude that a single numeral system is the normal situation: parallel numeral systems reflect a transitory language stage, where a borrowed system from a dominant language is ousting an original indigenous system (e.g., Matisoff 1997; Ahlers 2012). This certainly happens: Eurén's Finnish grammar (1851: 36) lists as the only structure an overcounting formation, e.g., kaksikolmatta (kaksi-kolm-at-ta [twothree-ORDINAL-PARTITIVE] 'two of the third') 'twenty-two', whereas the most recent modern reference grammar (Hakulinen et al. 2004) provides only the forma- 
tion of the type kaksikymmentäkaksi (kaksi-kymmen-tä-kaksi [two-ten-PARTITIVEtwo] 'two ( $x$ ) ten (+) two') (basically the same as in Swedish, which was the dominant language in Finland for several hundred years), and characterizes the pattern described by Eurén as obsolete.

The alternative that more than one numeral system is in stable use in a language, either as free or context-dependent variants, is not generally assumed in the literature, but this is perhaps at least in part an effect of the general paucity of sociolinguistic investigations in language documentation (see the papers in Hildebrandt et al. 2017).

For many of the earlier stages of modern standard languages we find descriptions of variant numeral systems. Some Slavic languages historically in contact with German used to have parallel alternative orderings of tens and ones in the numerals 21-99, according to de Bray (1969). This applied to Czech, Slovak, Slovene, and (Upper and Lower) Sorbian. Consulting more recent grammars of these languages, we find that generally only one ordering is given, with decades preceding 1-9 in Slovak, and units preceding decades in Slovene (M. L. Greenberg 2006: 57), Upper Sorbian (Šewc 1968) and Lower Sorbian (Jenč et al. 1978). However, Czech still allows both orderings (Naughton 2005: 116), and Janaš (1976) notes that in Lower Sorbian the alternative ordering still lingers on "[i]n älteren Schriften und vereinzelt in den Dialekten” (Janaš 1976: 146). A similar situation obtains in Norwegian, where both orderings are possible, the ordering with ones coming before tens due to Danish influence. Pre-Classical and Classical Latin allow both orders between tens and units, with or without a conjunction, making four possibilities, and complex numerals need not be contiguous, but allow other parts of the sentence to be interposed between their components, which is interpreted by de la Villa (2010: 221-222) as an indication that Latin numerals are considered as compositional phrases rather than lexical(ized) items. This could of course be true also in the case of Kanashi, that number building is felt by native speakers to be phrase building rather than strictly regimented word building. Note, however, that - as already mentioned - the Kanashi variation does not include alternative orders of components, ${ }^{16}$ with one small exception, viz. the construction where major parts of numerals are formed with the element sare '+half', which may precede or follow a multiple of 20.

According to Noreen (1904: 381), Old Swedish (1225-1526) composite numerals were formed according to the pattern "en (twēr, prīr u.s.w.) ok tiughu, en ok præ̈tigi u.s.w.” (i.e., [one (two, three, etc.) and twenty], [one and thirty]) and oc-

16 Although since both phrase- and clause-internal word order are generally fixed in Kanashi, this is not so surprising. 
casionally “fiughurtān ok tiughu 34, [...] siūtān ok tiughu 37” (i.e., [fourteen and twenty], [seventeen and twenty]). Modern Standard Swedish has as the only pattern the opposite order between tens and units (the same as English), and the vigesimal variant is completely unknown. A change must have occurred at some point between the Old Swedish period and today. Since language change is not instantaneous, there will presumably have been an interval with variation.

Comparing numeral structures across Indo-European languages, the most reasonable conclusion - given that we find varying structures but also that the atomic elements of these structures are by and large cognate - must be that ProtoIndo-European exhibited a good deal of variation in numeral formation (Winter 1992), not unlike what we see in present-day Kanashi.

Given that we find so many instances of parallel numeral systems even in a small and opportunistic survey of language descriptions - almost exclusively grammars, and not lexicons - why do we typically find one system in grammars of modern standard languages, and what are the impact of this on language documentation, if any?

We suspect that this may have to do with a normative conceptual framework connected to language standardization and unconsciously carried over into language description conducted by academic linguists, a special case of "written language bias in linguistics" (Linell 2005). It is well recognized that a central aspect of the creation of standard languages is reduction of variation; some variants are simply excluded from the standard (Joseph 1987: 126ff). Modern standard languages generally do not seem to recognize alternative numeral systems, for whatever reason.

First we note that, as a general rule, variation in the form of (near) synonymy is not a rare thing, even in modern standard languages, and part of the richness of the traditional numeral systems in Kanashi is due to the availability of alternative expressions - ST and IA - of the components of complex numerals. This can be seen as analogous to lexical synonymy. The existence of variant "synonymous" constructions - such as the parallel A and S patterns for forming Kanashi (and also Kinnauri) numerals - is also commonplace in languages, e.g. possession expressed using an ending or clitic vs. using an adposition, as in English Mary's mother the mother of Mary.

One reason for having synonyms seems to be variety for its own sake, and in the case of full or almost-full denotational synonyms, the alternatives may have different stylistic value or belong in different registers. In the case of numerals, the latitude for near-synonymy seems minimal, because the semantics of numerals are so narrow, and in a language standardization setting perhaps they may then be perceived more as something like spelling than grammar or even lexicon, meaning that variation will tend not to be normatively tolerated, and will also for 
this reason tend not to be recognized if it does occur outside of a normative setting, such as documenting an indigenous language.

If we do recognize that a language has alternative ways of expressing the same numeral and we think of this as a form of synonymy, the choice of variant may be dependent on stylistic factors or context of use, as with the Denjongke numeral systems mentioned above. ${ }^{17}$ Thus, Bender \& Beller (2007) report that Tongan complements a general, unrestricted decimal numeral system with a number of different vigesimal systems used for counting specific objects, typically different natural products of high cultural value in traditional Tongan society. Unfortunately, we are not in a position to say this about the Kanashi numeral variants attested in our material. All we have at the moment is the older language consultant's statement reproduced above to the effect that the alternative Kanashi numerals are interchangeable in all contexts, ${ }^{18}$ but this would need independent confirmation, preferably from a large body of natural-interaction data. Given that the younger language consultants were not familiar with any other numeral system than the Hindi-derived one, the prospects of acquiring such data are anything but bright.

\section{Discussion, summary and outlook}

As we have seen, despite their culturally isolationistic attitude, Kanashi speakers have traditionally had many and frequent opportunities for contact with IA speakers, and the language of interaction in such contacts has invariably been some IA language, traditionally "the language of Kullu" - Kullu Pahari - and now increasingly Hindi, as seen in the most recent Kanashi numeral system, where the elements are recognizable as having their origin in Hindi rather than Kullu Pahari.

One of the reasons for traditional regular interactions between Kanashi speakers and IA speakers is economic in nature, viz. that of collecting revenue and making offerings to the village gods. In such situations counting and numerals would be present at every turn, and these activities would always be conducted in an IA language, as they have been dominant languages in the region. At the same time everyday life in Malana - naturally conducted in Kanashi - by its nature did not

17 For example: for two of its cardinals, Swedish has two fully synonymous variants: två $\sim$ tvenne 'two' and tre trenne 'three'. However, the second member of each pair very clearly belongs to a formal, even slightly archaizing style and would be encountered in everyday (written or spoken) language only used jokingly.

18 Relevant in this context, Bender \& Beller (2007: 229-230) note that present-day Tongans tend to mix up and overgeneralize the traditional specific counting systems. 
provide many opportunities for counting beyond the lower numerals, so we may have at least part of the explanation for the massive borrowing of IA numerals in all the traditional numeral systems and the abandonment of all but the lowest ST numerals. See also Matisoff (1997: 12-16) and Matras (2011: 212-213).

The large variety of parallel numeral systems found in Kanashi may not be so rare among languages, but simply underreported, perhaps both because the relevant data are rare and difficult to come by, and because of an ideological bias introduced by language standardization, potentially distorting data collection procedures (Mazaudon 2010). At the same time, the language standardization mindset is gaining ground in the world, which means that this kind of variety in numeral systems is probably on its way out. In Kanashi this process happens through wholesale borrowing of Hindi numerals, rather than by selection of one of the extant variants, which serves to reinforce our impression that IA influence on Kanashi is increasing.

Finding out more about the history and current usage of the Kanashi multitude of numeral systems could certainly contribute to this neglected area of lexical typology, but - since numerals are easily borrowed, especially in unequal language contact situations (Matisoff 1997; Matras 2011) - time is running out, as both Comrie (2005) and Mazaudon (2010) remind us.

\section{References}

Ahlers, Jocelyn C. 2012. Two eights make sixteen beads: Historical and contemporary ethnography in language revitalization. International Journal of American Linguistics 78(4): 533-555.

Bailey, Thomas Grahame. 1908. The languages of the Northern Himalayas, being studied in the grammar of twenty-six Himalayan dialects. Asiatic Society monographs, Vol XII. London: The Royal Asiatic Society.

Bender, Andrea \& Sieghard Beller. 2007. Counting in Tongan: The traditional number systems and their cognitive implications. Journal of Cognition and Culture 7: 213-239.

Berger, Hermann. 1992. Modern Indo-Aryan. In Jadranka Gvozdanovic (ed.), Indo-European numerals, 243-288. Berlin: Mouton de Gruyter.

Blažek, Václav \& Michal Schwarz. 2016. Numerals in Mongolic and Tungusic languages - with notes to code-switching. Altai Hakpo - Journal of the Altaic Society of Korea 26: 131-155.

Comrie, Bernard. 1999. Haruai numerals and their implications for the history and typology of numeral systems. In Jadranka Gvozdanović (ed.), Numeral types and changes wordwide, 81-94. Berlin: Mouton de Gruyter.

Comrie, Bernard. 2005. Numeral bases. In Martin Haspelmath, Matthew Dryer, David Gil \& Bernard Comrie (eds.), The world atlas of language structures, 530-533. Also in: Matthew S. Dryer and Martin Haspelmath (eds), The world atlas of language structures online. 
Leipzig: Max Planck Institute for Evolutionary Anthropology. http://wals.info/chapter/131. Oxford: Oxford University Press.

de Bray, Reginald George Arthur. 1969. Guide to the Slavonic languages. 2nd edn. London: Dent.

de la Villa, Jesús. 2010. Numerals. In Philip Baldi \& Pierluigi Cuzzolin (eds.), New perspectives on Latin historical syntax 3. Constituent syntax: Quantification, numerals, possession, anaphora, 175-238. Berlin: De Gruyter Mouton.

Eurén, Gustaf Erik. 1851. Finsk språklära i sammandrag [A synopsis of Finnish grammar]. Turku: J. W. Lillja \& Co.

Greenberg, Joseph H. 1978. Generalizations about numeral systems. In Joseph H. Greenberg, Charles A. Ferguson \& Edith A. Moravcsik (eds.), Universals of human language. Vol. 3, 249-295. Stanford: Stanford University Press.

Greenberg, Marc L. 2006. A short reference grammar of Standard Slovene. Online publication: https://slaviccenters.duke.edu/projects/grammars. Durham: Duke Slavic Centers.

Grierson, George A. 1928. Linguistic survey of India, Vol 1, Part II: Comparative vocabulary. Calcutta: Government of India, Central Publication Branch.

Hakulinen, Auli, Maria Vilkuna \& Irja Alho. 2004. Iso suomen kielioppi [Large Finnish grammar]. Helsinki: Suomalaisen Kirjallisuuden Seura.

Hammarström, Harald. 2010. Rarities in numeral systems. In Jan Wohlgemuth \& Michael Cysouw (eds.), Rethinking universals: How rarities affect linguistic theory, 11-60. Berlin: Mouton de Gruyter.

Harcourt, Alfred Frederick Pollock. 1871. The Himalayan districts of Kooloo, Lahoul, and Spiti. London: Wm H. Allen \& Co.

Harris, Alice C. 2017. Multiple exponence. Oxford: Oxford University Press.

Hildebrandt, Kristine A., Carmen Jany \& Wilson Silva. 2017. Documenting variation in endangered languages. Language Documentation \& Conservation Special Publication No. 13. Available online: http://nflrc.hawaii.edu/ldc/sp-13-documenting-variation-endangeredlanguages/. Honolulu: University of Hawaii, Manoa.

Hodson, Thomas C. 1913. Note on the numeral systems of the Tibeto-Burman dialects. Journal of the Royal Asiatic Society of Great Britain and Ireland 45: 315-336.

Janaš, Pětr. 1976. Niedersorbische Grammatik. Bautzen: Domowina.

Jenč, Helmut, Irena Šěrakowa \& Horst Petrik. 1978. Grammatische Tabellen niedersorbisch. Gramatiske tabele dolnoserbski. Bautzen: Domowina.

Joseph, John Earl. 1987. Eloquence and power: The rise of language standards and standard languages. London: Pinter.

Konow, Sten. 1909. Linguistic survey of India, Vol 3: Tibeto-Burman family. Part I: General introduction, specimens of the Tibetan dialects, the Himalayan dialects, and the North Assam group. (This and several other volumes of the LSI were edited by Sten Konow, although published as the work of George A. Grierson). Calcutta: Government of India, Central Publication Branch.

Linell, Per. 2005. The written language bias in linguistics. First published in 1982 by Dept. of Communication Studies, University of Linköping, Sweden. London: Routledge.

Matisoff, James A. 1997. Sino-Tibetan numeral systems: Prefixes, protoforms and problems. Series B, Volume 114. Canberra: Pacific Linguistics.

Matisoff, James A. 2003. Handbook of Proto-Tibeto-Burman: System and philosophy of SinoTibetan reconstruction. Berkeley: University of California Press. 
Matras, Yaron. 2011. Universals of structural borrowing. In Peter Siemund (ed.), Linguistic universals and language variation, 204-233. Berlin: De Gruyter Mouton.

Mazaudon, Martine. 2010. Number-building in Tibeto-Burman languages. In Stephen Morey \& Mark Post (eds.), North East Indian linguistics, volume 2, 117-148. New Delhi: Cambridge University Press India.

Menninger, Karl. 1969. Number words and number symbols: A cultural history of numbers. Cambridge: MIT Press.

Naughton, James. 2005. Czech: An essential grammar. London: Routledge.

Noreen, Adolf. 1904. Altschwedische Grammatik mit Einschluss des Altgutnischen. Halle: Niemeyer.

Pitkin, Harvey. 1984. Wintu grammar. Berkeley: University of California Press.

Pitkin, Harvey. 1985. Wintu dictionary. Berkeley: University of California Press.

Saxena, Anju. 2017. Sangla Kinnauri. In Graham Thurgood \& Randy J. LaPolla (eds.), The SinoTibetan languages, 2nd edn., 756-772. London: Routledge.

Saxena, Anju. 2022. The linguistic landscape of the Indian Himalayas: Languages in Kinnaur. Forthcoming 2022. Leiden: Brill.

Šewc, Hinc. 1968. Gramatika hornjoserbskeje rěče. 1. zwjazk: fonematika a morfologija [A grammar of Upper Sorbian. Vol. 1: Phonetics and morphology]. Budyšin: Domowina.

Sharma, Devi Datta. 1992. Tribal languages of Himachal Pradesh. Part two. Delhi: Mittal Publications.

STEDT. 2016. James A. Matisoff et al. The Sino-Tibetan etymological dictionary and thesaurus. Available online at: http://stedt.berkeley.edu/search. Berkeley: University of California.

Thomas, Frederick W. 2011. Research notes on the Zhangzhung language by Frederick W. Thomas at the British Library. In Tsuguhito Takeuchi, Burkhard Kessel \& Yasuhiko Nagano (eds.), Senri ethnological reports 99, 1-246. Osaka: National Museum of Ethnology.

Tobdan. 2011. Exploring Malana: An ancient culture hidden in the Himalayas. New Delhi: Indus Publishing Company.

Turner, Ralph L. 1966. A comparative dictionary of the Indo-Aryan languages. Available online: http://dsal.uchicago.edu/dictionaries/soas/. Oxford: Oxford University Press.

Weiers, Michael. 2003. Moghol. In Juha Janhunen (ed.), The Mongolic languages, 248-264. London: Routledge.

Widmer, Manuel. 2017. A grammar of Bunan. Berlin: De Gruyter Mouton.

Winter, Werner. 1992. Some thoughts about Indo-European numerals. In Jadranka Gvozdanovic (ed.), Indo-European numerals, 11-28. Berlin: Mouton de Gruyter.

Yliniemi, Juha. 2019. A descriptive grammar of Denjongke (Sikkimese Bhutia). Helsinki: University of Helsinki. (PhD thesis).

Zeisler, Bettina. 2011. Kenhat, the dialects of Upper Ladakh and Zanskar. In Mark turin \& Bettina Zeisler (eds.), Himalayan languages and linguistics: Studies in phonology, semantics, morphology and syntax, 235-301. Leiden: Brill. 


\section{A Attested Kanashi numerals in our fieldwork data}

The following list shows those Kanashi numerals which occur in our fieldwork data, except Hindi numerals. ${ }^{19}$ Elements of IA origin in the Kanashi column are set in boldface with underlining.

\begin{tabular}{|c|c|c|}
\hline 1 & iid & \\
\hline & $e k$ & \\
\hline 2 & nif & \\
\hline 3 & fum & \\
\hline 4 & $p u$ & \\
\hline 5 & $\eta a$ & \\
\hline & $n a$ & \\
\hline & pãt & \\
\hline 6 & $t^{h} a$ & \\
\hline 7 & sat & \\
\hline 8 & $\overline{a t^{h}}$ & \\
\hline 9 & nao & \\
\hline 10 & das & \\
\hline 11 & gjara & \\
\hline 12 & $\underline{\text { bara }}$ & \\
\hline 13 & tera & \\
\hline 14 & toda & \\
\hline 15 & pandra & \\
\hline 16 & sola & \\
\hline 17 & sutara & \\
\hline & fumis kam nidza & [3:is less 20] \\
\hline 18 & $t^{h a r a}$ & \\
\hline & nif kam nicka & [2 less 20] \\
\hline 19 & unni & \\
\hline & i:dis kam nicka & [1:is less 20$]$ \\
\hline 20 & $\frac{b i}{\text { nitka }}$ & \\
\hline 21 & ikki & \\
\hline & nidkau dze i:d & [20:u plus 1] \\
\hline 22 & nickau dze nif & [20:u plus 2] \\
\hline 23 & $\begin{array}{l}\text { nickau dze fum } \\
\text { teis }\end{array}$ & [20:u plus 3] \\
\hline 24 & $t g o b(b) i$ & \\
\hline 25 & $\begin{array}{l}\text { nidza dze } \eta a \\
\operatorname{pat}((t) i\end{array}$ & [20:u plus 5] \\
\hline
\end{tabular}

\begin{tabular}{|c|c|c|}
\hline 26 & $\frac{t^{h} a b(b) i}{t^{h} a b b i s}$ & \\
\hline \multirow[t]{2}{*}{27} & nickau dze sat & [20:u plus 7] \\
\hline & fumis kam $\overline{\operatorname{de}}$ bija & [3:is less 30] \\
\hline \multirow[t]{2}{*}{28} & nickau dze $\overline{a t^{h}}$ & [20:u plus 8] \\
\hline & nifis kam derbija & [2:is less 30] \\
\hline \multirow[t]{2}{*}{29} & nickau dze nao & [20:u plus 9] \\
\hline & i:dis kam derbija & [1:is less 30] \\
\hline \multirow[t]{2}{*}{30} & $\frac{d e[b i j a}{t i:(s)}$ & {$[1.5: 20]$} \\
\hline & 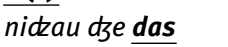 & [20:u plus 10] \\
\hline 1 & $\begin{array}{l}\text { nickau gjara } \\
\text { ikkatis }\end{array}$ & [20:u 11] \\
\hline \multirow[t]{2}{*}{32} & nickau dze bara & [20:u plus 12] \\
\hline & $\frac{a t^{h} i s}{\text { batti }}$ kam trali & [8:is less 40] \\
\hline 3 & $\begin{array}{l}\overline{\text { nickau dze tera }} \\
\text { teti } \\
\text { tetu }\end{array}$ & [20:u plus 13] \\
\hline \multirow[t]{2}{*}{37} & 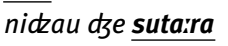 & [20:u plus 17] \\
\hline & fumis kam tgali & [3:is less 40] \\
\hline \multirow[t]{2}{*}{38} & nickau dze $\underline{t^{h} \text { ara }}$ & [20:u plus 18] \\
\hline & nifis kam tyali & [2:is less 40] \\
\hline \multirow[t]{2}{*}{39} & nickau dze unni & [20:u plus 19] \\
\hline & i:dis kam tali & [1:is less 40] \\
\hline
\end{tabular}

40 tali nif nicka [2(x) 20]

43 tgaliu dze fum [40: u plus 3] sat kam pudza [7 less 50] nif nickau Jum [2 (x) 20:u (+) 3]

44 taliu dze $p u \quad$ [40:u plus 4] thas kam pudza [6:s less 50] nif nickau pu [2(×) 20:u (+) 4]

19 We exclude only such IA numerals which are identical to the corresponding Hindi items while not found in Kullu Pahari. 
45 tyaliu dze na nif nickau dze na nis nickau na

46 tgaliu dze $\underline{t}^{\text {h } a}$ nif nickau dze $\boldsymbol{t}^{h} \boldsymbol{a}$ nis nickau $\underline{\boldsymbol{t}^{h} \boldsymbol{a}}$

48 taliu dze $\underline{a t^{h}}$ nifis kam pucka nif nickau at ${ }^{h}$

49 tyaliu dze nao i:dis kam pucka nif nickau nao

\section{0 pucka}

taliu dze das

55 nif nidzau dze pandra nais kam sat ${ }^{h}$ pãt kam sat ${ }^{h}$

59 i:dis kam sat nif nickau dze unni

60 Jum nicka $\mathrm{Sat}^{h}$ $\mathrm{sat}^{\mathrm{h}}$

$61 \overline{\text { ikat }}^{h}$

$62 \overline{\text { sat }^{h} u}$ dze nif Jum nidkau dze nif

64 sat $^{h} u$ dze pu

65 Jum nidzau dze na Jum nickau na

67 sat ${ }^{h} u$ dze sat Jum nidzau dze sat fumis kam sare sat $t^{h}$

68 sat ${ }^{h} u$ dze $a t^{h}$ Jum nidzau dze at ${ }^{h}$ nifis kam sare sat ${ }^{h}$

69 Jum nidzau dze nao sat ${ }^{h} u$ dze nao sat $^{h} u$ dze nao i:dis kam sare sat ${ }^{h}$ [40:u plus 5]

[2 (x) 20:u plus 5]

[2 (x) 20:u (+) 5]

[40:u plus 6]

[2 (x) 20:u plus 6]

[2 (x) 20:u (+) 6]

[40:u plus 8]

[2:is less 50]

[2 (x) 20:u (+) 8]

[40:u plus 9]

[1:is less 50]

[2 (x) 20:u (+) 9]

[40:u plus 10]

[2 (x) 20:u plus 15]

[5:is less 60]

[5 less 60]

[1:is less 60]

[2 (x) 20:u plus 19]

[3 (x) 20]

[60:u plus 2]

[3 (x) 20:u plus 2]

[60:u plus 4]

[3 (x) 20:u plus 5]

[3 (x) 20:u (+) 5]

[60:u plus 7]

[3 (x) 20:u plus 7]

[3:is less + half 60]

[60:u plus 8]

[3 (x) 20:u plus 8]

[2:is less + half 60]

[3 (x) 20:u plus 9]

[60:u plus 9]

[60:u plus 9]

[1:is less + half 60]
70 sat $^{h} u$ dze das sat ${ }^{h}$ uke das

sare sat ${ }^{h}$

74 tha $^{\text {kam afi }}$

ts $^{\text {ha }}$ kam afi

76 sat $^{h} u$ dze sola

Jum nickau dze sola

80 a $i$

pu nicka

81 afiu dze i:d unnis kam Jo

pu nidzau dze i:d

82 afiu dze nif

tharais kam Jo pu nickau dze nif

85 afiu dze na pu nickau dze na

87 afiu dze sat teras kam fo pu nickau dze sat

88 afiu dze at ${ }^{h}$ baras kam fo pu nickau dze at ${ }^{h}$

89 a fiu dze nao gjaras kam fo pu nickau dze nao

90 afi sare afiu das nabbe

99 i:dis kam \o pu nidkau dze unni

100 Jo

101 fo i:d i.d Sou i'd

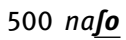
naso [60:u plus 10] [60:u:ke 10] [+half 60]

[6 less 80]

[6 less 80]

[60:u plus 16]

[[3 (x) 20:u plus 16]

[4 (x) 20]

[80:u plus 1]

[19:s less 100]

[4 (x) 20:u plus 1]

[80:u plus 2]

[18:is less 100]

[4 (x) 20:u plus 2]

[80:u plus 5]

[4 (x) 20:u plus 5]

[80:u plus 7]

[13:s less 100]

[4 (x) 20:u plus 7]

[80:u plus 8]

[12:s less 100]

[4 (x) 20:u plus 8]

[80:u plus 9]

[11:s less 100]

[4 (x) 20:u plus 9]

[80 +half]

[80:u (+) 9]

[1:is less 100]

[4 (x) 20:u plus 19]

[100 (+) 1]

[1 (x) $100(+)$ 1]

[5(x)100]

[5(x)100] 